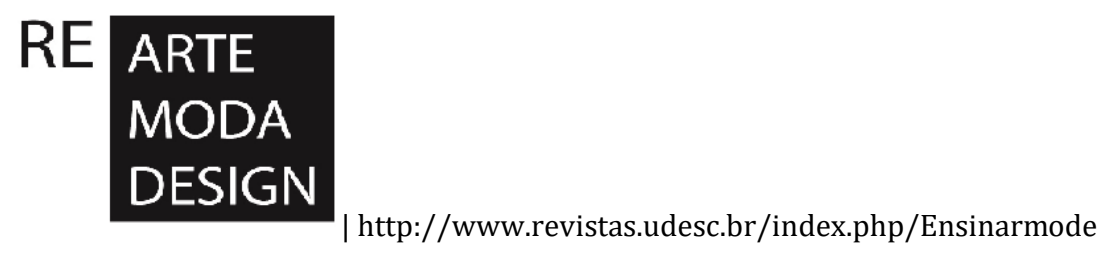

\title{
A INCLUSÃO DA PESSOA COM DEFICIÊNCIA VISUAL NO ENSINO SUPERIOR: DESIGN DE MODA E O MÉTODO SEE BEYOND.
}

\author{
The inclusion of people with visual impairment in higher education: Fashion \\ Design and the SEE BEYOND Method.
}

Geraldo Coelho Lima Júnior ${ }^{1}$

\section{RESUMO}

O presente artigo apresenta o Método SEE BEYOND a partir de uma abordagem em que é tratada a Inclusão da pessoa com deficiência visual nos bacharelados de Design de Moda. Para tanto fundamenta-se, de início, nas ações governamentais que visam a promover a inserção da pessoa com deficiência na sociedade e, mais especificamente, no Ensino Superior. Em paralelo, com o propósito de evidenciar lacunas e barreiras, que dificultam o acesso do grupo apontado ao referido curso, a pesquisa traz a contexto revisão bibliográfica acerca do ingresso desses estudantes nesse nível de ensino. Identificam-se as necessidades para o desenvolvimento de método que promova a acessibilidade de estudantes à educação, na área do Design de Moda, o que inclui o desenvolvimento de material didático-pedagógico acessível, como integrante do método desenvolvido. São também mostrados os resultados obtidos após o desenvolvimento do método e sua aplicação junto a estudantes com e sem deficiência visual, considerados em grupos específicos.

Palavras-chave: Design de Moda. Inclusão. Pessoa com Deficiência Visual.

\footnotetext{
${ }^{1}$ Doutor e Mestre em Design, pela Universidade Anhembi Morumbi, onde também concluiu a PósGraduação Latu Senso em Neurociência aplicada à Educação (2016) e em Moda, Arte e Cultura. Designer de moda e figurino, graduado em Desenho Industrial pela UEMG. E-mail: glimadesign58@gmail.com | Lattes: http://lattes.cnpq.br/7822446597426824

Revista ENSINARMODE, Florianópolis, Vol. 2, N. 1, Fevereiro-Maio 2018, p. 029-056. DOI: http://dx.doi.org/10.5965/25944630212018029 | ISSN 2594-4630
} 


\title{
RE ARTE \\ MODA \\ DESIGN \\ | http://www.revistas.udesc.br/index.php/Ensinarmode
}

\begin{abstract}
This article sets out the SEE BEYOND method as an approach for addressing the question of including students with visual impairment in Fashion Design degree courses. To start with, it investigates government measures that seek to encourage the inclusion of handicapped people in society, and in particular, in Higher Education. The objective of the research is to find evidence of the shortcomings and obstacles that can prevent certain groups from obtaining access to these courses, while at the same time, conducting a review of the literature with regard to the enrolment of students at this academic level. An attempt was made to define the needs for devising a method that can make it easier for students to gain access to education in the area of Fashion Design. This includes the preparation of suitable didactic/pedagogical material as an integral part of the method employed. There is also an examination of the results obtained after the method had been formulated and its application to both students with and without visual impairments, who were treated in separate groups.
\end{abstract}

Keywords: Fashion Design; Inclusion; Students with Visual Impairment. 


\section{RE ARTE \\ MODA \\ DESIGN}

\section{INTRODUÇÃO}

O desenvolvimento de projetos em Design de Moda solicita do estudante a aprendizagem de todas as etapas do processo, pelas quais passa na formação acadêmica. Nela se inserem pesquisas teóricas referenciais, seguidas da apropriação, para obter dados que possibilitem a materialização de uma coleção de moda.

Decorrente de observações acerca das metodologias apresentadas aos discentes que se vinculam ao Design de Moda, foram notadas lacunas no que tange ao processo de ensino-aprendizagem capaz de proporcionar a formação de pessoas com deficiência visual (PcDV) nessa área. A partir da revisão bibliográfica identificou-se a inexistência de método que forneça informações a PcDV de maneira a Ihe possibilitar atuação no desenvolvimento do projeto de uma coleção.

Tais investigações deram-se, ainda, por meio de estudos de matrizes curriculares de bacharelados em Design de Moda, existentes em território nacional de Instituições Federais de Ensino Superior (IfES) e Instituições de Ensino Superior (IES) privadas, realizados entre 2014 e 2016. Buscou-se localizar nessas ementas algum direcionamento que promovesse a inclusão de pessoas com deficiência visual na área em questão. Essa fase da pesquisa seguiu parâmetros que determinavam a denominação do curso como: Bacharelado em Design de Moda e conceito 4,0 ou superior junto ao MEC. Ao final do período indicado e, a partir dos parâmetros, foi composta uma lista de 12 instituições entre IfES e IES apresentada na tabela a seguir. 


\section{RE ARTE \\ MODA \\ DESIGN}

| http://www.revistas.udesc.br/index.php/Ensinarmode

Tabela 1: Lista final Bacharelados Design de Moda/Brasil. A tabela apresenta os resultados de uma pesquisa a partir de dados apresentados pelo MEC. A lista apresenta os cursos que contemplaram os parâmetros estabelecidos.

\begin{tabular}{|c|l|c|c|}
\hline \multicolumn{3}{|c|}{ CIDADE/UF } & INSTITUIÇÕES DE ENSINO SUPERIOR - CURSO DESIGN DE MODA \\
\hline SÃO PAULO/SP & FAAP & DESIGN DE MODA & BACHARELADO \\
\hline SÃO PAULO/SP & FEBASP & DESIGN DE MODA & BACHARELADO \\
\hline SÃO PAULO/SP & UAM & DESIGN DE MODA & BACHARELADO \\
\hline PRESIDENTE PRUDENTE/SP & FAPEPE/UINESP & DESIGN DE MODA & BACHARELADO \\
\hline BELO HORIZONTE/MG & UFMG & DESIGN DE MODA & BACHARELADO \\
\hline UBERLÂNDIA/MG & UNITRI & DESIGN DE MODA & BACHARELADO \\
\hline CURITIBA/PR & PUC/PR & DESIGN DE MODA & BACHARELADO \\
\hline CURITIBA/PR & UTP & DESIGN DE MODA & BACHARELADO \\
\hline LONDRINA/PR & UEL & DESIGN DE MODA & BACHARELADO \\
\hline TTAJAII MIRIM/SC & UNIASSELVI & DESIGN DE MODA & BACHARELADO \\
\hline PORTO ALEGRE/RS & UNIRITTER & DESIGN DE MODA & BACHARELADO \\
\hline GOIÂNIA/GO & UFG & DESIGN DE MODA & BACHARELADO \\
\hline
\end{tabular}

Fonte: Acervo do autor.

Foi de interesse nesta pesquisa observar os bacharelados em todo o território nacional. Em virtude dos parâmetros estabelecidos, nem todas as regiões do país estão contempladas.

Foram estudadas diversas pesquisas, focadas na inserção da pessoa com deficiência $(P c D)$ e a $P c D V$, desde o ensino fundamental até o superior nos cursos de graduação tecnológica ou bacharelado. Em maior proporção destacam-se aquelas voltadas ao ensino fundamental, seguida por pesquisas direcionadas ao ensino médio e superior, respectivamente.

Nelas, direcionou-se o foco para a questão da inclusão social da pessoa com deficiência visual no Ensino Superior. Neste texto dispõem-se os resultados desses estudos e a importância deles para direcionar o desenvolvimento do método SEE $B E Y O N D$, resultado de trabalho realizado em dezoito meses, com pessoas com deficiência visual.

Este texto propõe-se a enfocar as pesquisas voltadas ao Ensino Superior, ainda que ocasionalmente possam ser citadas referências que contemplem aquelas que visam aos demais níveis de ensino. O pressuposto para o foco citado conectase aos bacharelados em Design de Moda. Nesse sentido, esta revisão apresenta resultados que relacionam a pessoa com deficiência e o Ensino Superior, por aderência e contextualização relativa à criação de metodologia de ensino em Design de Moda, a saber, o Método SEE BEYOND. O método, que será oportunamente 


\section{RE ARTE \\ MODA \\ DESIGN}

abordado, visa a atender à necessidade de formação de conhecimento, relativo ao Design de Moda, de um público formado por pessoas com deficiência visual e potencializar as possibilidades de desenvolvimento de projetos junto a estudantes videntes.

É crescente o número de estudantes ingressantes nas universidades, tanto no Brasil como no exterior. Contudo, é necessário o aparelhamento das instituições de ensino com relação a: a) material acessível; b) adequação de espaços físicos coletivos das faculdades e universidades; c) necessidade da presença de um corpo docente capacitado para o ensino de pessoas com deficiência (CASTRO; ALMEIDA, 2014). Tais fatores desenham a relevância, quando se constata que neles reside uma das dificuldades para o acesso da pessoa com deficiência $(P c D)$ ao ensino no Brasil.

Ressalta-se, como fundamental, o esclarecimento no que tange à definição de uma pessoa com deficiência e todas as possíveis implicações, deveres e direitos que são destinados àqueles que se encontram nessa condição ou que acompanham essas pessoas. Apresenta-se esse assunto na próxima seção, assim como se passa a trazer os programas de cunho governamental voltados a essa parcela da população brasileira.

\section{A LEI BRASILEIRA DE INCLUSÃO DA PESSOA COM DEFICIÊNCIA (ESTATUTO DA PESSOA COM DEFICIÊNCIA) - LEI 13.146}

A Lei $13.146^{2}$ tem como tema principal as pessoas com deficiência. Aprovada em 06 de julho de 2015, versa a respeito de direitos e liberdade, capazes de promover escolhas em relação ao ensino como um processo inclusivo, motivo pelo qual devem ser acatados. Em seu Art. 2ํㅡ, a lei define a pessoa com deficiência como:

Aquela que tem impedimento de longo prazo de natureza física, mental, intelectual ou sensorial, o qual, em interação com uma ou mais barreiras, pode obstruir sua participação plena e efetiva na sociedade em igualdade de condições com as demais pessoas. (BRASIL, 2015)

\footnotetext{
2 Todas as inserções sobre a lei têm como fonte o Livro I, Parte geral, Título I, Disposições preliminares, Capítulo I, Disposições gerais e serão citadas como: BRASIL, 2015. 


\section{RE ARTE \\ MODA \\ DESIGN}

| http://www.revistas.udesc.br/index.php/Ensinarmode

Tal artigo reconhece diferenças e registra a interação com barreiras enfrentadas pela PcD; elas impactam o cotidiano dessas pessoas em suas atividades diárias, assim como podem comprometer a relação do estudante com deficiência e as instituições de ensino, públicas ou privadas.

Acessibilidade e tecnologias assistivas são itens destacados pela lei. Nesse âmbito, entende-se a acessibilidade como "possibilidade e condição de alcance para utilização, com segurança e autonomia, de espaços, mobiliários, equipamentos urbanos, edificações, transportes, informação e comunicação, inclusive seus sistemas e tecnologias" (BRASIL, 2015), sem deixar de considerar serviços e instalações públicas ou privadas, em zonas urbanas ou rurais que necessitam ser acessíveis à $\mathrm{PcD}$.

Já a tecnologia assistiva refere-se a distintos produtos, recursos, ou metodologias e práticas que promovam "funcionalidade, relacionada à atividade e à participação da pessoa com deficiência ou com mobilidade reduzida, visando à sua autonomia, independência, qualidade de vida e inclusão social” (BRASIL, 2015).

Necessário ainda salientar a importância do desenho universal, na criação de produtos ou serviços que venham a ser usados por pessoas com deficiência sem que sejam necessárias adaptações naqueles já existentes, ou seja, que sejam concebidos de modo a capacitar a inclusão, sem distinção.

Com relação às barreiras, estas são descritas como qualquer tipo de obstáculo, atitude ou comportamento que comprometa a vida da $P c D$, e são identificadas como: a) urbanísticas; b) arquitetônicas; c) nos transportes; d) nas comunicações e na informação; e) atitudinais; f) tecnológicas (BRASIL, 2015).

Salienta-se também a importância da comunicação como forma de interação entre os cidadãos e, nesse âmbito, trata das opções existentes voltadas para as PcD como a "Língua Brasileira de Sinais (Libras); a visualização de textos, o Braille; o sistema de sinalização ou de comunicação tátil, os caracteres ampliados, os dispositivos multimídia, assim como a linguagem simples, escrita e oral” (BRASIL, 2015), dentre outros pontos relativos às tecnologias da informação e das comunicações, já observados na sociedade, porém em muitos casos, infelizmente, o que se tem é a instituição de leis sem o devido apreço por sua aplicação. 


\section{RE ARTE \\ MODA \\ DESIGN}

| http://www.revistas.udesc.br/index.php/Ensinarmode

A acessibilidade é questão que caminha em paralelo a outras de igual importância no tocante à Educação, como as tecnologias assistivas e o material didático. São citadas simultaneamente as tecnologias assistivas e o desenho universal por caminharem na promoção da igualdade em meio à diversidade.

A Lei 13.146 ainda registra que os deveres com relação à $P c D$ expandem-se para além do Estado, com abrangência à sociedade e suas partes, na garantia dos direitos dessa parcela da população. Na soma de tais direitos contempla-se a formação básica de conhecimento e sua ampliação, fundamentada nos avanços da civilização humana.

No Capítulo IV, que trata do direito à Educação, garante-se o acesso a um sistema educacional inclusivo em todos os níveis ao longo da vida. Destaca-se a importância do desenvolvimento intelectual, dos talentos e das habilidades da PcD como "dever do Estado, da família, da comunidade escolar e da sociedade" na garantia de uma educação de qualidade, "colocando-a a salvo de toda forma de violência, negligência e discriminação. (BRASIL, 2015).

É preciso dizer que as barreiras ainda são muitas. A lei não é acompanhada de ampla divulgação, capaz de atingir a sociedade e suas instituições de modo a garantir direitos à maior parcela de pessoas com deficiência, pois elas estão em posição de baixa renda na escala socioeconômica (LIMA, 2006). A permanência desse quadro repercute na manutenção de uma situação em que muitos estudantes com deficiência matriculados não frequentam as instituições de ensino.

A Lei 13.146 ainda contempla outros pontos relevantes, tais como: a) sistema educacional inclusivo; b) aprimoramento dos sistemas educacionais; c) projetos pedagógicos igualitários; d) adoção de medidas que garantam acesso e permanência da PcD no ensino em todos os níveis educacionais; e) desenvolvimento de métodos e técnicas pedagógicas inclusivas; f) formação de professores ${ }^{3}$.

O item [b] explicita uma discussão presente em pesquisas de diferentes autores. Rossetto (2009) comenta que, apesar da existência de leis que garantam o acesso da pessoa com deficiência ao Ensino Superior, ainda existem barreiras que

\footnotetext{
${ }^{3}$ São citados os pontos que mais diretamente se relacionam ao contexto tratado no presente texto. (Texto completo: http://www.planalto.gov.br/ccivil_03/_ato2015-2018/2015/lei/113146.htm). 


\section{RE ARTE \\ MODA \\ DESIGN}

dificultam a adoção de uma política realmente mais efetiva em relação ao assunto. Por sua vez, Barros (2013) indica a carência de materiais, recursos e equipamentos adaptados, entre fatores que implicam na qualidade do ensino-aprendizagem.

"Estamos incluídos nesta sociedade humana pelo princípio da identidade, mas podemos ser excluídos pelo princípio da diversidade. Aí reside a nossa contradição" (LIMA, 2006, p.20). Uma importante barreira a ser transposta diz respeito à diversidade. A reflexão sobre os processos inclusivos precisa considerar diferenças físicas, intelectuais e culturais.

A compreensão, a respeito de inclusão e exclusão, deve ser considerada prioritária, para que se desfaça o pressuposto da desigualdade em busca da inserção que seja comum para qualquer cidadão. Tal desigualdade está presente nas diferenças de "classe social e de poder econômico e político (LIMA, 2006, p.21). A diversidade e a igualdade não são opostas; na verdade, tal embate se estabelece entre "a desigualdade socialmente construída [...] que se opõe à igualdade" (LIMA, 2006, p.21), no contexto em que uns são melhores que os outros, em uma sociedade.

Esse pensamento estabelecido compromete a Educação inclusiva quando o diferente é considerado inferior, no tocante a habilidades e interesses da pessoa com deficiência visual (LIMA, 2006; NUNES e LOMÔNACO, 2010). Questiona-se a viabilização da equidade no Ensino com a supressão de barreiras, o que ocorrerá ao se investir na completa acessibilidade (CASTRO e ALMEIDA, 2014).

Faz-se necessário: adequar um programa de ensino que contemple a diversidade de estudantes; habilitar o corpo docente para lidar com as diferenças; compartilhar - entre os estudantes, com e sem deficiências - o material didático que atenda às diferentes necessidades; e contemplar metodologias para a aplicação desses itens. Entra em pauta a inclusão e, sob essa premissa, insere-se a participação do estudante com deficiência em ambiente escolar regular em busca de diminuir as diferenças.

Em consonância com necessidades peculiares à pessoa com deficiência, o Governo Federal instituiu, em 2004, o Programa INCLUIR que "cumpre o disposto nos decretos $n^{\circ} 5.296 / 2004$ e $n^{\circ} 5.626 / 2005$ e no edital INCLUIR 04/2008" (http://portal.mec.gov.br/), que será apresentado e discutido na seção seguinte. 


\section{RE ARTE \\ MODA \\ DESIGN \\ | http://www.revistas.udesc.br/index.php/Ensinarmode}

\section{O PROGRAMA “INCLUIR”}

O programa INCLUIR, instituído em 2005, antecede a Lei Brasileira de Inclusão da Pessoa com Deficiência (BRASIL, 2015). Como programa de governo tem buscado agir para minimizar barreiras relativas ao ingresso dessa parcela da população ao Ensino Superior, em especial nas instituições federais. Apesar de não haver em seu texto qualquer menção às Instituições de Ensino Superior (IES) privadas, elas ficam igualmente responsáveis de seguir as diretrizes previstas para a inclusão social da pessoa com deficiência.

Desde 1994, já existia no Brasil a política de inclusão da pessoa com deficiência no ensino. Com o Programa INCLUIR realizou-se a revisão no texto até então seguido, para adequá-lo e ser possível acompanhar as mudanças sociais e educacionais. As bases que fundamentam o programa adotam o que dispõe o Documento Orientador - Programa INCLUIR - Acessibilidade na Educação Superior - SECADI/SESu-2013 (BRASIL, 20134).

Neste documento incluem-se instituições estaduais e municipais, assim como as privadas; entendia-se que, com o crescimento das IES no Brasil, abrir-se-iam mais vagas para a pessoa com deficiência no Ensino Superior. Por outro lado, Rossetto (2009, p.93) ressalta que tal crescimento tem levado a "um comprometimento do significado da educação como bem público de qualidade e de valor social". Nesse sentido, a abertura de portas para o ensino superior possibilita a entrada de todo estudante, porém se veem defasagens entre a quantidade e a qualidade do que é ofertado. Na tabela a seguir verifica-se o aumento de matrículas entre 2003 e 2011 (BRASIL, 2013).

Tabela 2 - Comparativo do número de matrículas de pessoas com deficiência nos anos de 2003 e 2011.

\begin{tabular}{|c|c|}
\hline \multicolumn{2}{|c|}{ O Censo da Educação Básica - MEC/INEP } \\
\hline \multicolumn{2}{|c|}{ Educação Superior - Número de Matrículas } \\
\hline 2003 & 2011 \\
\hline 5078 & 23250 \\
\hline
\end{tabular}

Fonte: http://portal.mec.gov.br/programa-incluir 


\section{RE ARTE \\ MODA \\ DESIGN \\ | http://www.revistas.udesc.br/index.php/Ensinarmode}

As leis regulatórias, instituídas pelo governo federal, seguem diretrizes internacionais. Contudo o processo inclusivo, que precisa abranger vários aspectos concernentes à acessibilidade, ainda não encontrou respostas no ambiente educacional. Observa-se a carência de recursos direcionados às práticas pedagógicas adequadas (LIMA, 2006; ROSSETTO, 2009). A questão do acesso é das mais discutidas entre pesquisadores de várias áreas e inserida nos documentos oficiais governamentais, porém Barros (2013, p.45) afirma que "a inclusão vem sendo utilizada como forma de superação da ordem social, sendo apresentada como solução para a exclusão social".

Tal fato, que deveria ser cumprido, não é devidamente seguido, não apenas pelas Instituições de Ensino Superior, como também no Instrumento de Avaliação de Cursos de Graduação presencial e à distância do Ministério da Educação - esse item não impacta a avaliação dos cursos.

Como professor de IES posso identificar a ausência de determinados recursos relativos a tecnologia assistiva ou material didático acessível, em especial para as pessoas com deficiência visual (PcDV), foco principal deste artigo. Castro e Almeida (2014, p.187) constataram, a partir de entrevistas semiestruturadas com pessoas com deficiência, obstáculos relativos a: locomoção, acesso a serviços de higiene e segurança; identificaram a ausência de sinalização adequada e mapas táteis para pessoas com deficiência visual, também identificada por Lima (2006, p.77).

Segundo o Censo $2010^{5}$, na população brasileira constavam mais de 45 milhões de pessoas com deficiências. Desse total, entre 18 e 19 anos, idade com a qual normalmente os estudantes ingressam nas universidades, havia 6.632.922 jovens, e dentre eles 798.921 possuíam algum tipo de deficiência, como demonstra a tabela a seguir.

${ }^{5} \mathrm{ftp}$ ://ftp.ibge.gov.br/Censos/Censo_Demografico_2010/Caracteristicas_Gerais_Religiao_Deficiencia/t ab1_3.pdf 


\section{RE ARTE \\ MODA \\ DESIGN}

| http://www.revistas.udesc.br/index.php/Ensinarmode

Tabela 2 - Censo Demográfico 2010.

\begin{tabular}{|c|c|c|c|}
\hline \multicolumn{5}{|c|}{ Censo demográfico 2010 - Características Gerais da População - Resultados da Amostra } \\
\hline \multicolumn{2}{|c|}{ População residente, por tipo de deficiência, segundo a situação do domicilio e os grupos de idade - Brasil - 2010 } \\
\hline \multicolumn{2}{|c|}{ Não consegue de modo algum } & Grande dificuldade & Alguma dificuldade \\
\hline Total & 506.377 & 6.056 .533 & 29.211 .482 \\
\hline 0 a 4 anos & 20.935 & 24.707 & 122.581 \\
\hline 5 a 9 anos & 21.407 & 97.719 & 1.286 .971 \\
\hline 10 a 14 anos & 24.058 & 175.176 & 1.357 .295 \\
\hline 15 a 19 anos & 24.457 & 195.493 & 821.618 \\
\hline 15 a 17 anos & 14.475 & 117.495 & 1.473 .070 \\
\hline 18 e 19 anos & 9.981 & 77.998 & 535.677 \\
\hline 20 a 24 anos & 29.808 & 210.571 & \\
\hline
\end{tabular}

Fonte: https://goo.gl/5b1Cyz

Do montante, constavam 87.979 pessoas com deficiência visual total ou com muita dificuldade de ver, ou 623.656 - se incluídas as PcDV com alguma dificuldade visual. Esse número cresce em 1.713.449 pessoas, totalizando 2.337.105, quando são somados aos jovens entre 20 e 24 anos, idade em que os estudantes ingressam ou estão em andamento de seus cursos de Ensino Superior; e, segundo o que determina o programa INCLUIR, poderiam ingressar em qualquer "área de seu interesse profissional".

Com base nesses dados direciona-se o foco na seção a seguir para a educação superior da pessoa com deficiência visual, seu ingresso e permanência nas IfES e IES.

\section{O ENSINO SUPERIOR E A PESSOA COM DEFICIÊNCIA VISUAL}

Aqui se expõe uma proposta - decorrente de muitas outras pesquisas realizadas por este autor - que se inicia com a identificação da necessidade da pessoa com deficiência visual de reconhecimento de peças de roupa e suas cores em uma loja; prossegue com entendimento da ausência de conhecimento por parte desse grupo de pessoas a respeito de Moda e Design; levanta a possibilidade de formação de repertório a respeito do Design de Moda, seus processos projetuais e 


\section{RE ARTE \\ MODA \\ DESIGN}

lançamentos de coleções de moda e vestuário com vistas a propor o ensino de uma metodologia projetual a ser adotada em contexto acadêmico, contemple os estudantes com deficiência visual e também contribua para a potencialização no desenvolvimento de projetos dos estudantes videntes.

Já descritos em Lima Júnior (2008), são reconhecidos, basicamente, três níveis de deficiência em relação à visão: a) a baixa visão, possivelmente relacionada a algum tipo de doença; b) a deficiência visual adquirida - pode ser decorrente de um acidente ou mesmo a evolução de um quadro presente em uma pessoa com visão subnormal; c) a deficiência visual congênita.

Retomam-se os dados do Censo 2010 na tabela a seguir. Ela apresenta, mais especificamente, a relação de pessoas com deficiência visual na faixa etária correspondente aos estudantes ingressantes ou aqueles que cursam o Ensino Superior.

Tabela 3 - Deficiência Visual - Critérios de análise do Censo 2010.

\begin{tabular}{|c|c|c|c|}
\hline \multicolumn{5}{|c|}{ DEFICIÊNCIA VISUAL } \\
\hline Faixa etária & Não consegue de modo algum & Grande dificuldade & Alguma dificuldade \\
\hline 18 e 19 anos & 9.981 & 77.998 & 1.473 .070 \\
\hline 20 a 24 anos & 29.808 & 210.571 & 1.540 .445 \\
\hline
\end{tabular}

Fonte: https://goo.gl/5b1CyZ

Ferrari e Campos (2001) propõem outra subdivisão para a acuidade visual, diferença que pode trazer forte impacto ao longo da vida de uma pessoa com deficiência visual.

Visão normal: entre $51 \%$ e $70 \%$ de visão

Visão quase normal: entre $31 \%$ e $50 \%$ de visão

Visão subnormal moderada: entre $11 \%$ e $30 \%$ de visão

Visão subnormal severa: entre $6 \%$ e $10 \%$ de visão

Visão subnormal profunda: entre $3,4 \%$ e $5 \%$ de visão

Cegueira: Quase cegueira - 1,2\% de visão

Cegueira total - ausência de percepção de luz

Visão Subnormal: indivíduos que apresentam desde condições de indicar projeção de luz, até o grau em que a acuidade visual interfere ou limita seu desempenho (FERRARI; CAMPOS, 2001, p.41)

Com esses dados ficam mais evidentes divisões e capacidades visuais das pessoas. Para o desenvolvimento do método, o objetivo é deter as investigações relativas ao que as autoras assinalam como a "Visão subnormal moderada" e a "Cegueira total" (FERRARI; CAMPOS, 2001). 


\section{RE ARTE \\ MODA \\ DESIGN}

| http://www.revistas.udesc.br/index.php/Ensinarmode

Para Oliveira (2007) os recursos pedagógicos, usados para estudantes com deficiência visual, dividem-se entre os ópticos (estímulo à PcDV com baixa visão) e os não ópticos (ausência total de visão), como segue na Tabela 5. Contudo nem sempre o mesmo recurso óptico atende a diferenças existentes na acuidade visual de indivíduos distintos com baixa visão. Pessoas com baixa visão utilizam ambos os recursos.

Tabela 5 - Recursos pedagógicos.

\begin{tabular}{|l|l|}
\hline \multicolumn{2}{|c|}{ RECURSOS PEDAGÓGICOS } \\
\hline Recursos não ópticos & Recursos ópticos \\
\hline Sistema Braille & Grafia ampliada \\
\hline Máquina de datilografar Braille para escrita manual & $\begin{array}{l}\text { Contraste (de cores entre texto e plano de } \\
\text { fundo) }\end{array}$ \\
\hline $\begin{array}{l}\text { Reglete (instrumento praille) } \\
\text { Branina (para obter boa visilidade) }\end{array}$ \\
\hline Impressora Braille & Lentes e lupas \\
\hline Sintetizadores de voz & $\begin{array}{l}\text { CCTV - Closed Circuit (amplia } \\
\text { imagem) }\end{array}$ \\
\hline Cubarítimo (estrutura sentenças matemáticas) & Ampliador de tela de computadores \\
\hline Soroban (instrumento de cálculo) & \\
\hline Gravador de voz & \\
\hline Bengala longa & \\
\hline Acesso ao computador/internet & \\
\hline
\end{tabular}

Fonte: Acervo do autor.

Tais recursos são fundamentais em todas as escolas, para um acompanhamento adequado, ou de uso pessoal, como no caso da bengala longa. Nem sempre as instituições de ensino estão devidamente equipadas - nos níveis fundamental, médio ou superior - sejam públicas ou privadas. Dessa maneira, fica comprometida a acessibilidade pela PcDV, em três contextos: a) espacial, ou ao ambiente; b) material didático; c) ensino.

\subsection{Acessibilidade espacial.}

Um dos primeiros itens observados, no tocante à acessibilidade da pessoa cega, refere-se ao espaço circundante. Trata-se de aprendizado que contempla as atividades da vida diária e aos poucos implica em ações motoras, de locomoção e outras atitudes da pessoa com deficiência visual. Segundo Lima (2006, p.79), "Para 


\section{RE ARTE \\ MODA \\ DESIGN}

a pessoa cega, a superação da dificuldade de locomoção precisa ser enfrentada e construída cotidianamente".

$\mathrm{Na}$ vivência de um estudante com deficiência visual, uma questão preponderante refere-se ao acesso ao ambiente escolar e o reconhecimento dos espaços coletivos das instituições. Os ambientes de uma IES ou de uma IfES precisam estar adequados para receber a PcDV, com sinalização que garanta autonomia no deslocamento entre todos os espaços da instituição, o que implica locomover-se entre os espaços; reconhecer as distâncias; identificar entradas dos edifícios; situar-se nos espaços internos; localizar as salas de aula; posicionar-se em mesa ou carteira para acompanhar as aulas. Realizar essas tarefas com autonomia trata-se de superação das barreiras arquitetônica e espacial já mencionadas, tanto na Lei 13.146 (BRASIL, 2015), quanto no Programa INCLUIR (BRASIL, 2013) do Ministério de Educação e Cultura.

\subsection{Acessibilidade ao material didático.}

São muitas as barreiras e, acima de tudo, deve ser considerada a opção feita pelo estudante em relação ao curso. Naqueles em que a teoria se sobrepõe à prática, Castro e Almeida (2014) comentam que "para os alunos com deficiência visual, as principais dificuldades referem-se às informações que são passadas em murais ou na lousa da sala de aula" e aí podem ser incluídas também as aulas que usam recursos audiovisuais e que não são acompanhadas de audiodescrição.

Esse último exemplo ocorre igualmente nos cursos teórico-práticos. docente, muitas vezes, recorre ao uso de material didático não adaptado para o público enfocado. Muitos dos recursos ópticos e não ópticos são necessários para o acompanhamento das disciplinas pelo estudante com deficiência visual.

A instituição deve fornecer, quando necessário, material em braille ou com audiodescrição e, como está presente na Lei 13.146 (BRASIL, 2015), assim como adaptar currículos, métodos, técnicas pedagógicas e avaliações, para um aprendizado adequado. As solicitações por parte do candidato a uma vaga em curso superior podem acontecer desde o processo seletivo, e as instituições precisam se preparar para tais situações. 


\section{RE ARTE \\ MODA \\ DESIGN \\ | http://www.revistas.udesc.br/index.php/Ensinarmode}

\subsection{Acessibilidade ao ensino: o papel do docente.}

"A concepção de cego com base no vidente, além de minimizar as possibilidades de entender o cego como ele realmente é, enfatiza suas limitações e não suas possibilidades" (NUNES e LOMÔNACO, 2010, p.7). É possível não haver a compreensão adequada sobre as necessidades desses discentes em sala de aula.

A formação dos professores é um dos aspectos importantes para o aprendizado da PcDV, dentre eles a "individualização" - cada estudante é único em capacidades e habilidades; e a concretização, ou seja, a possibilidade de oferecer à pessoa com deficiência visual o reconhecimento de um objeto concreto (BARROS, 2013). Aliados a eles ressaltam-se o "estímulo adicional" que propõe estimular a pessoa com deficiência visual em seu processo de ensino-aprendizagem, e a "autoatividade", ou a conquista de autonomia do próprio conhecimento aliados às experiências do discente. O material didático acessível estimula e potencializa o aprendizado, na medida em que proporciona aprendizado eficiente pelo discente com deficiência visual.

A descrição de referências visuais pelo professor possibilita ao estudante construir, mentalmente, relações com espaço, objetos e outras pessoas. Os demais sentidos sensoriais mostram-se importantes, embora não sejam substitutos da visão (LIMA JÚNIOR, 2016). Cabe ao docente avaliar capacidades, habilidades e necessidades do estudante.

\section{DESIGN DE MODA E NEUROEDUCAÇÃO: O MÉTODO SEE BEYOND}

O método SEE BEYOND fundamenta-se nessas pesquisas, em virtude de sua importância ao direcionar-se para o ensino superior às pessoas com deficiência. Porém, concomitantemente foram empreendidos os seguintes estudos: a) o design e suas diretrizes curriculares nacionais; b) o ensino do Design de Moda nas IES e IfES - essa etapa ocorreu por meio da análise das matrizes curriculares e ementas de cursos de Design de Moda, selecionados em todo o território nacional; c) as neurociências, cujos fundamentos permitiram o entendimento a respeito das funções cerebrais, propiciando subsídios para que se compreendesse o comportamento da 


\section{RE ARTE \\ MODA \\ DESIGN}

| http://www.revistas.udesc.br/index.php/Ensinarmode

PcDV na relação com o ensino-aprendizagem; a neuroeducação, que une os conhecimentos das neurociências, da psicologia, da pedagogia, com vistas ao desenvolvimento de modelos e métodos de ensino para os estudantes com ou sem deficiência visual.

Todo esse referencial teórico visa a apresentar o método, segundo um de seus pilares: a Inclusão da pessoa com deficiência visual no Ensino Superior.

O método SEE BEYOND fundamenta-se em quatro princípios (Tempo, Forma, Cor e Composição), que se apoiam nos quatro pilares descritos para a constituição de três módulos: Fundamentação; Potencialização; Materialização. Estes foram aplicados inicialmente junto a um grupo de pessoas com deficiência visual (Grupo Análise PcDV), durante dezoito meses, e, posteriormente, foi validado quando de sua aplicação a dois grupos de estudantes da Universidade Anhembi Morumbi (Grupo Análise, composto por vinte e dois estudantes; e Grupo Controle, por trinta e um estudantes), durante um semestre letivo.

Os pilares são inter-relacionados, o que possibilita a condução de cada módulo a partir de conteúdos agregados de forma não linear, isto é, recupera-se, quando necessário, cada tema tratado em cada encontro presencial durante a aplicação do método. Isso implica em que a apreensão, em um momento, não deve ser perdida ao longo da construção de conhecimento, pois conteúdos teóricos e práticos convivem em cada tema abordado, e o material didático acessível encontrase sempre presente, em apoio à consolidação do aprendizado na memória, para que simultaneamente sejam esclarecidas dúvidas acerca do que é ministrado.

Desenvolve-se, assim, outra dinâmica em que se inscreve a interdisciplinaridade na construção desse processo de ensino-aprendizagem. Foram estudadas as disciplinas selecionadas, que envolvem conteúdos essenciais relativos à história da moda, tecnologias têxteis, design, os elementos formais de um projeto. Desde a concepção, o método previu a necessidade de elaboração de material didático acessível e que, ao mesmo tempo, propiciasse a formação de conhecimento por meio da interação entre conteúdo, recursos pedagógicos e a PcDV. 


\section{RE ARTE \\ MODA \\ DESIGN}

| http://www.revistas.udesc.br/index.php/Ensinarmode

Tabela 6 - Esta tabela apresenta uma representação gráfica da Estrutura do Método See Beyond. Nela estão presentes os Princípios que se associam aos Pilares na constituição dos três módulos que orientam o método: Fundamentação; Potencialização; Materialização.

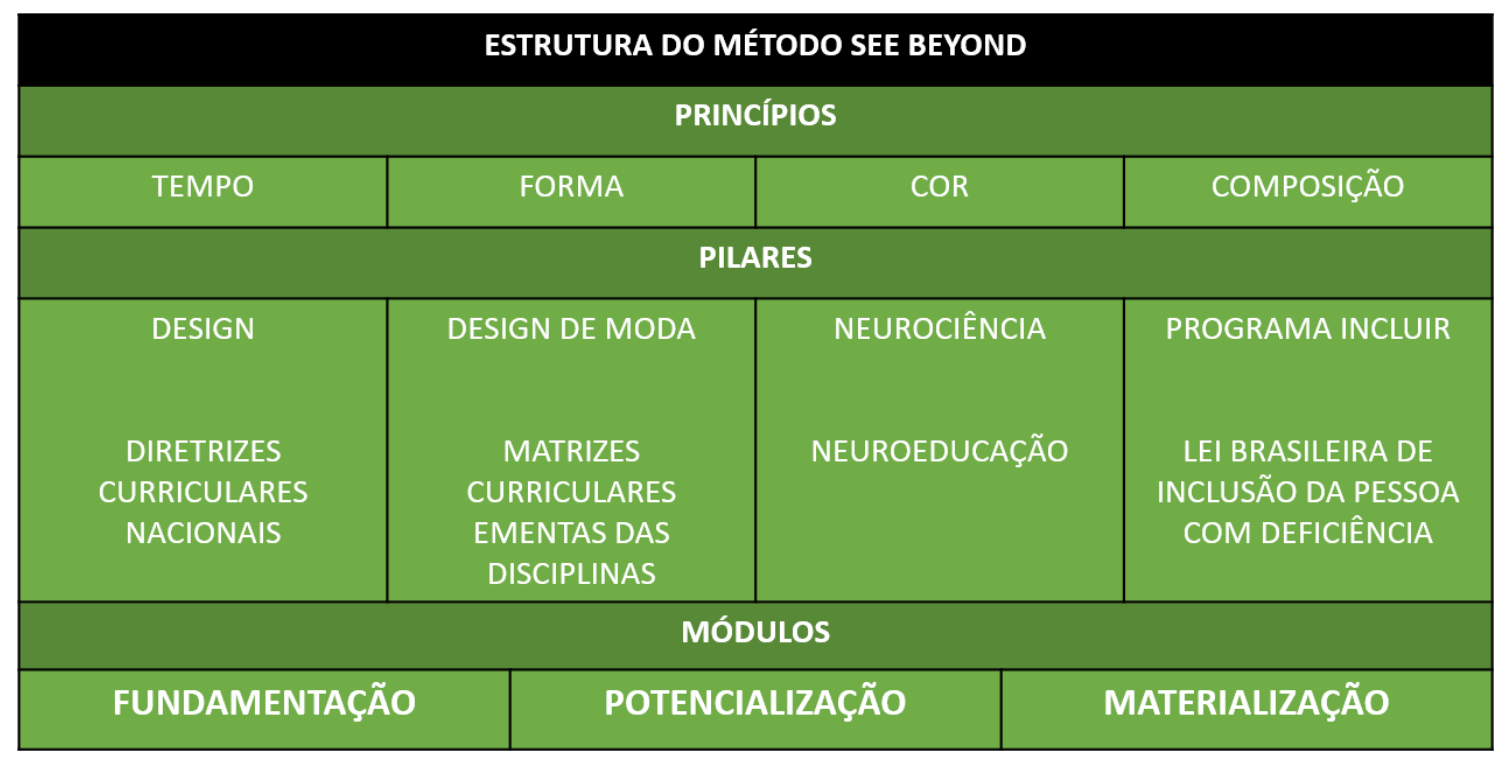

Fonte: Acervo do autor.

Como conferido, muitas iniciativas foram feitas para promover a inclusão da PcDV no Ensino Superior. Em relação aos bacharelados em Design de Moda, não foram identificadas disciplinas de metodologia de projeto que contemplassem a inclusão desse grupo de pessoas. Tal fato se deve à existência de barreiras para o acesso desses estudantes aos cursos de design de moda, tais como: a) ausência de recursos e material pedagógico; b) inexistência de um método que pudesse ser aplicado junto a PcDV que lhes garantisse o aprendizado necessário para o desenvolvimento de projetos de coleção; c) limites de comunicação existentes na relação docente $X$ discente com deficiência visual; d) despreparo das IES para o acolhimento adequado de estudantes nas condições descritas.

Buscou-se com o método: a) aproximar a pessoa com deficiência visual do design de moda ao relacionar os elementos que compõem esse universo (BERLIM, 2011; CASTILHO, 2009; CRANE, 2011; FIORINI, 2008); b) apresentar à PcDV os recursos que o design oferece, gerando compreensão e conhecimentos relativos à área de maneira a desenvolver e ampliar o repertório desse público a respeito de moda (CIPINIUK e PORTINARI, 2006; LÖBACH, 2001; MATTÉ, 2008; RECH, 2015);

c) propiciar a assimilação das bases formais no tocante a vestuário, design, comportamento e uso (FLETCHER, 2011; FORNASIER, 2008; MARTINS, 2008; 


\section{RE ARTE \\ MODA \\ DESIGN}

NASCIMENTO, 2012); d) habilitar a PcDV a reconhecer as características de peças de roupa - os elementos formais projetuais - assim como possibilitar a construção de autoimagem em paralelo à percepção de adequação da roupa ao corpo do usuário (GUIMARÃES, 2000; SORGER e UDALE, 2009); e) estimular a PcDV para que compreenda e identifique as propostas do vestir, aliadas aos novos desenvolvimentos da indústria têxtil e de confecção (AVELAR, 2009; CHATAIGNIER, 2006; CLARKE e MAHONY, 2007; SALTZMAN, 2004, 2008).

Figura 1 - As cinco imagens apresentam detalhes de distintos recursos pedagógicos empregados na aplicação do método: em sentido horário, frutas e legumes trazem etiquetas em braille com as cores; silhueta é mostrada a partir de uma estrutura de espartilho; boneco articulado é reproduzido em desenho em relevo; trama e urdume têxteis ampliados permitem o reconhecimento das estruturas de um tecido; formas geométricas traduzem as relações entre bidimensionalidade $e$ tridimensionalidade.
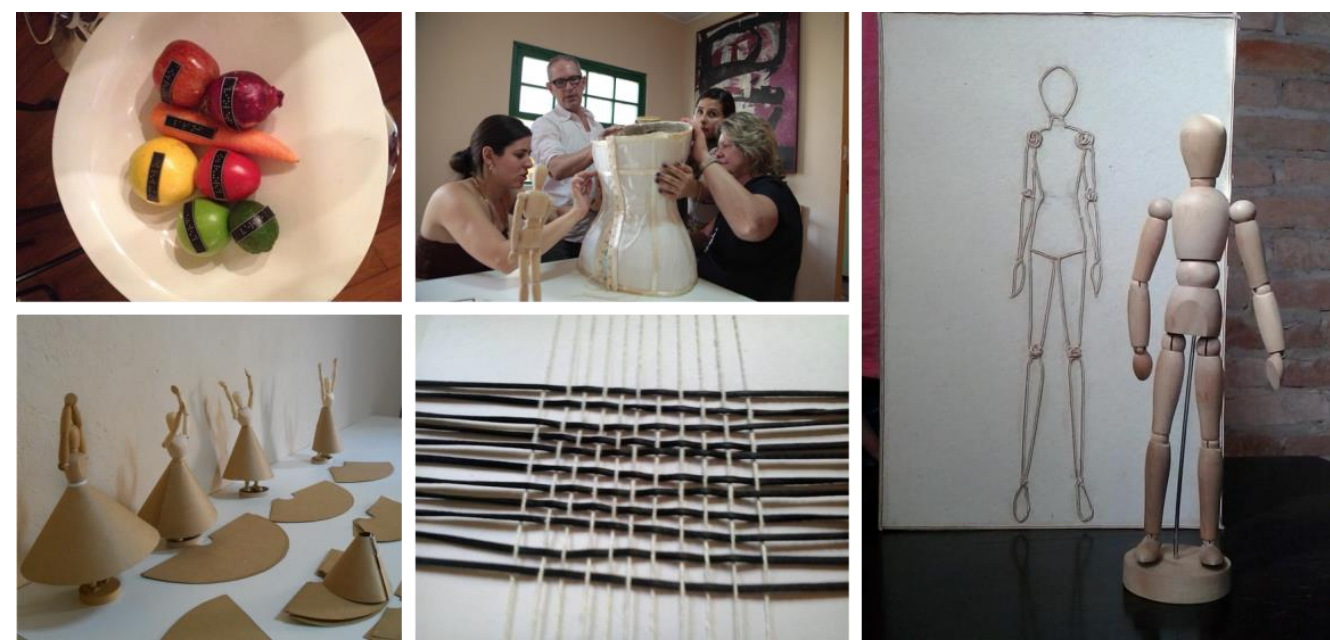

Fonte: acervo do autor

O título do presente método é formado por um acrônimo, no que tange ao fonema SEE, composto pelos verbos to Stimulate, to Educate e to Enlarge, associado à preposição BEYOND (além de). Ampliar os estímulos experienciados pelo estudante, com ou sem deficiência visual, potencializa o processo de ensinoaprendizagem e expande a percepção dos elementos projetuais necessários ao desenvolvimento de coleções em design de moda.

Faz-se necessário ressaltar que para o desenvolvimento do método SEE $B E Y O N D$ inserem-se de modo expressivo os estudos voltados para a relação entre a Neurociência e a Educação. Por meio deles foi possível elaborar e propor, junto 


\section{RE ARTE \\ MODA \\ DESIGN}

aos grupos de estudantes com e sem deficiência visual, outra possibilidade prática de desenvolvimento de metodologia projetual.

Das pesquisas efetivadas por este autor sobre os estudos desenvolvidos por neurocientistas (DAMÁSIO, 2004, 2011, 2012; TOKUHAMA-ESPINOZA, 2008; SACKS, 2010; COSENZA \& GUERRA, 2011; IZQUIERDO, 2011), identificou-se a relevância da Neuroeducação, nesse processo, como apoio à elaboração de material e recursos didáticos, capazes de promover mais compreensão das informações relativas ao Design de Moda, por parte de pessoas com deficiência visual. Esses estudos são importantes também ao se reconhecer a necessidade de mudança dos modelos de ensino até então praticados por este autor, fiel a um modus operandi pautado na difusão de conteúdos pertinentes às disciplinas, sem atentar às peculiaridades existentes no comportamento dos estudantes.

"Sabemos que [na espécie humana] não existem dois cérebros iguais", afirmam Cosenza e Guerra (2011: p.27). Essa citação reflete a necessidade de compreensão relativa à maneira como essas diferenças aparecem, quando se estuda o funcionamento cerebral relativo às pessoas com ou sem deficiência visual, ao considerar que "o cérebro é o órgão da aprendizagem" (COSENZA, GUERRA, 2011, p.142).

Assim, aliaram-se os conhecimentos provenientes desse outro campo, a Neuroeducação, na condução dos processos de ensino-aprendizagem em Design de Moda, ao reconhecer a importância dessa área a ser incorporada ao presente método, que passou a contar como um dos pilares que o sustentam.

Conceitos específicos estruturam o método SEE BEYOND. Dentre eles destacam-se: a) recursos pedagógico-andragógicos acessíveis à PcDV precisam ser empregados, em substituição aos recursos visuais; b) recursos pedagógicoandragógicos táteis devem considerar a facilidade de manuseio dos materiais; c) recursos pedagógico-andragógicos táteis precisam ser dimensionados em escala que permita a acessibilidade das peças desenvolvidas; d) o material didático pode ser complementado com recursos auditivos, olfativos, gustativos e motores; e) a leitura de textos teóricos pode ser feita pelo professor, de modo a fornecer fundamentação teórica ao que é apresentado em aula. 


\section{RE ARTE \\ MODA \\ DESIGN}

| http://www.revistas.udesc.br/index.php/Ensinarmode

O conhecimento a respeito das funções cerebrais pode auxiliar o planejamento de aulas em um curso de Design de Moda; ele é considerado fundamental, assim como os conceitos neurocientíficos que identificam os processos cerebrais, como é possível identificar nas laterais dos triângulos na Figura 2, na medida em que contribuem para a elaboração de recursos pedagógicos acessíveis, na seleção de material didático - textos, gravações em áudio, e todo referencial necessário ao estudo e à pesquisa - e ainda no modo como todo esse material será aplicado a cada uma das aulas, tendo em vista o conteúdo programático a ser seguido.

Figura 2 - Representação gráfica dos Módulos do Método SEE BEYOND.

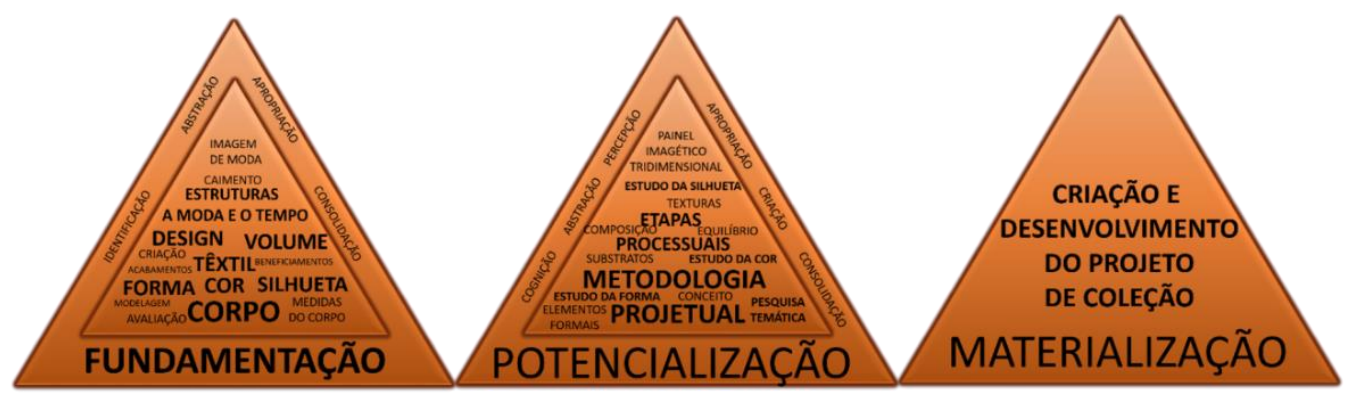

Fonte: Acervo do autor.

O método SEE BEYOND foi aplicado inicialmente junto a um grupo de estudantes com deficiência visual durante 18 meses, período no qual se desenvolveram os três módulos. Em sequência, outros dois grupos com estudantes sem deficiência visual - Grupo Análise e Grupo Controle - foram submetidos ao método durante um semestre letivo. Identificou-se mais interesse e motivação por parte desses estudantes, assim como melhor percepção do corpo e do espaço, essencial para o desenvolvimento de projetos e melhor aproveitamento do processo de ensino aprendizagem e apropriação da Metodologia Projetual resultando em mais qualidade dos processos projetuais.

\section{RESULTADOS}

Dentre os resultados obtidos, destacam-se:

(1) evocação de memórias - potencializa a assimilação e o aprendizado dos conteúdos por estudantes com e sem deficiência visual. 


\section{RE ARTE \\ MODA \\ DESIGN}

| http://www.revistas.udesc.br/index.php/Ensinarmode

Ao apresentar novos conteúdos o docente precisa considerar as memórias individuais e as coletivas de todos os estudantes. Nesse caso é importante que elas sejam estimuladas, recuperadas e associadas ao conteúdo. "Memória' significa aquisição, formação, conservação e evocação de informações. A aquisição é também chamada de aprendizado ou aprendizagem: só se 'grava' aquilo que foi aprendido." (ISQUIERDO, 2011, p.11). Nesse sentido é necessário que as memórias possam ser trabalhadas dentro do contexto em cada disciplina. Tal resgate, seja de um estudante ou compartilhado por todos em uma sala de aula, são importantes na medida em que trazem contribuições para o aprendizado de todos. O estabelecimento de relações entre as memórias e as novas informações impulsiona a formação de outras memórias ou, como cita Isquierdo (2011), em outras palavras, gravam-se novos conteúdos.

Figura 3 - Apresentação de modelagem e identificação de suas partes com o corpo da estudante com deficiência visual.
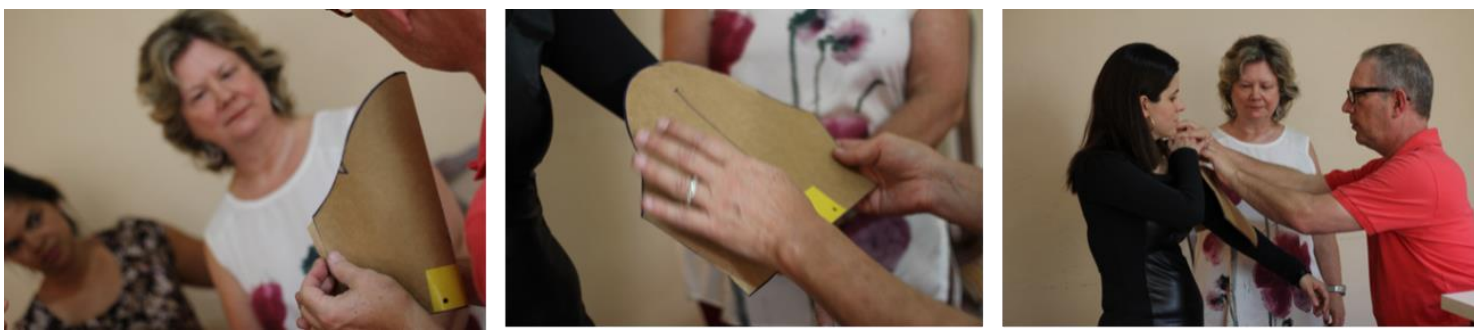

Fonte: Acervo do autor.

(2) estímulos somatossensoriais propiciam a acessibilidade ao material didático por discentes com deficiência visual, ao mesmo tempo em que ampliam o interesse dos alunos videntes pelos conteúdos ministrados, com a criação de imagens mentais individuais. Segundo Damásio (2011, p.98):

As imagens se baseiam em mudanças que ocorrem no corpo e no cérebro durante a interação física de um objeto com o corpo. Sinais enviados por sensores localizados em todo o corpo constroem padrões neurais que mapeiam a interação do organismo com o objeto.

Depreende-se, pelo que aponta Damásio (2011), que os estímulos podem ser provenientes de várias fontes, e participam da criação de imagens mentais. A associação entre os estímulos e os sentidos sensoriais propicia a apreensão de conteúdos ministrados; possibilita e potencializa o aprendizado; gera mais interesse 


\section{RE ARTE MODA DESIGN}

| http://www.revistas.udesc.br/index.php/Ensinarmode

por parte do estudante, com ou sem deficiência visual; e traz, como consequência, um processo de materialização do projeto mais consistente, na medida em que as memórias consolidadas (decorrentes desse processo) sejam evocadas, e participem produtivamente de mais outra etapa do desenvolvimento projetual. Entende-se, desse modo, a ocorrência de interação entre vários eventos - a percepção dos estímulos; a ação dos sentidos sensoriais; a apreensão de conteúdos; a consolidação e a posterior evocação de memórias - que ocorrem em distintas regiões cerebrais. O resultado dessa interação liga-se a uma experiência satisfatória no contato com os objetos, o ambiente circundante e as informações passadas pelo docente, no que tange ao estudante com deficiência visual, e mais participação e interesse nas atividades projetuais tanto por aquele com deficiência quanto pelo vidente.

Figura 4: Estudo de formas e sua relação com o corpo, por estudantes com deficiência visual.

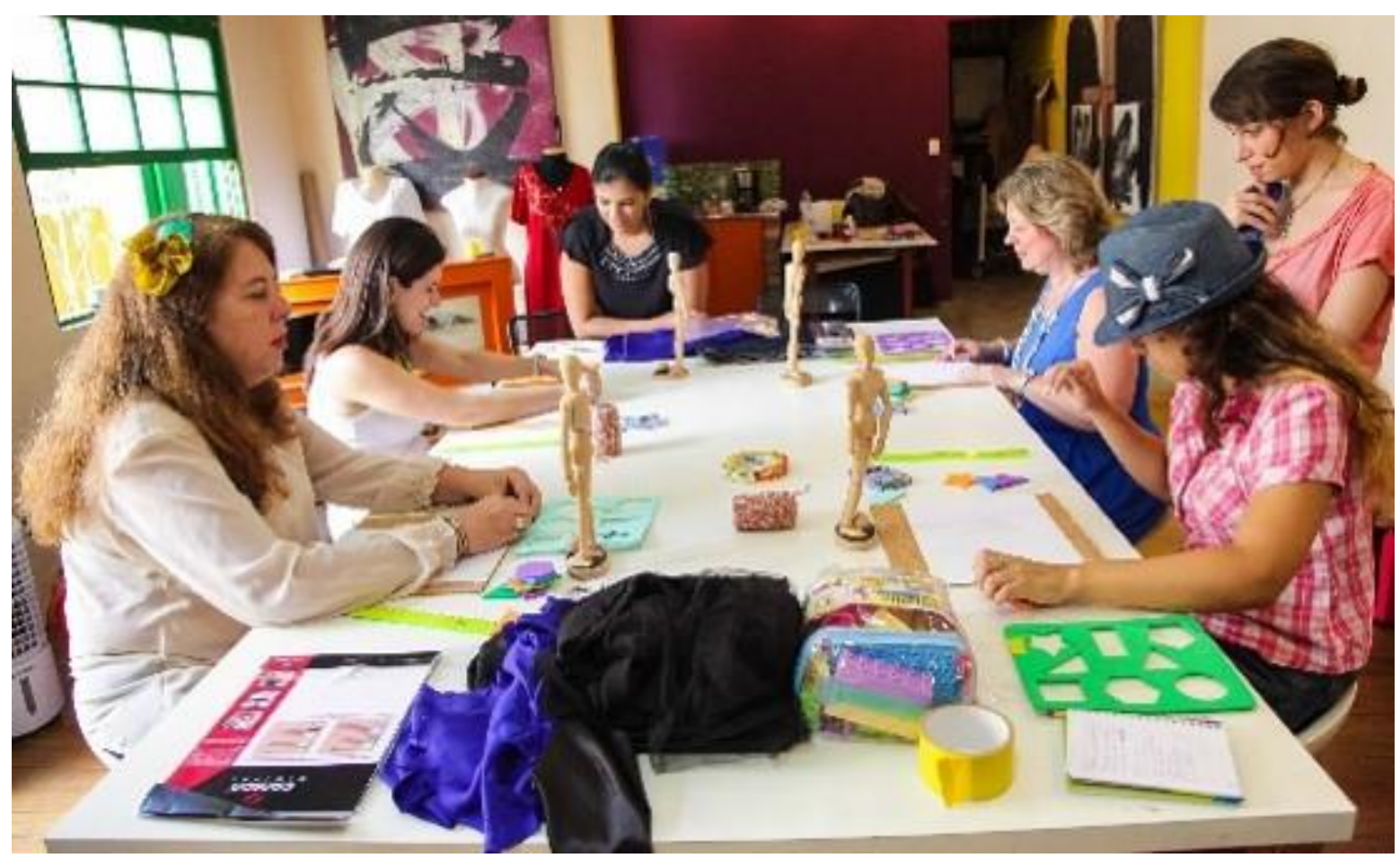

Fonte: acervo do autor.

(3) repertórios pessoais, quando associados ao método de desenvolvimento projetual, potencializam o aprendizado pela valorização de habilidades dos discentes com e sem deficiência visual. Ainda, deve ser destacada sua contribuição social, ao possibilitar a inclusão de PcDV aos cursos de Design de Moda. 


\section{RE ARTE \\ MODA \\ DESIGN}

| http://www.revistas.udesc.br/index.php/Ensinarmode

As experiências individuais são necessárias no processo de ensinoaprendizagem. O que é vivenciado pelo corpo, seu contato com distintos objetos no ambiente circundante, é registrado por mapas mentais formados no cérebro. Assim, ao entrar em contato com novos conteúdos, ministrados em sala de aula, todo o corpo participa do momento do aprendizado, assimilado pelo cérebro e consolidado em sua memória. "O que normalmente denominamos memória de um objeto é a memória composta das atividades sensitivas e motoras relacionadas à interação entre o organismo e o objeto durante dado tempo" (DAMÁSIO, 2011, p.169). Nesse contexto, memórias, ou repertórios individuais, somam-se às novas memórias e constituem o conhecimento que será necessário, aqui, ao desenvolvimento de um projeto em Design de Moda.

Figura 5 - Apresentação de proposta criativa com definição de materiais, por estudante com deficiência visual.
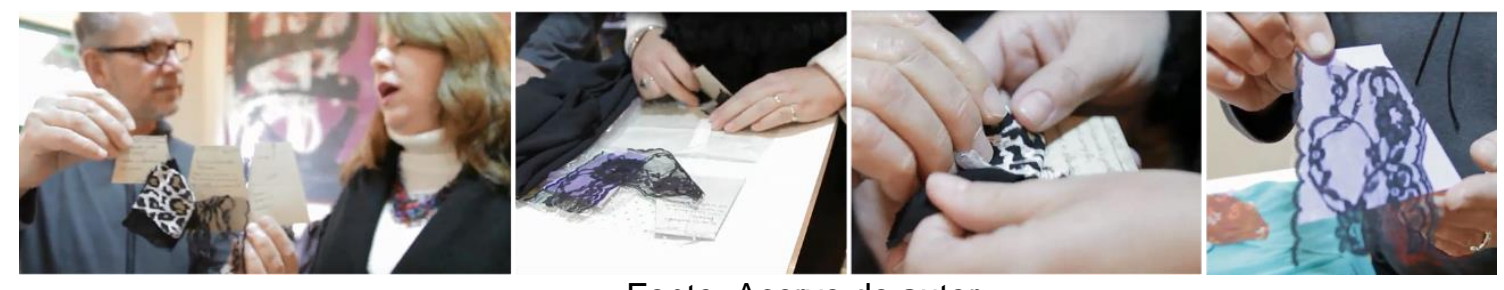

Fonte: Acervo do autor.

Convém registrar que a apreensão de novos conteúdos está diretamente interligada com o método de ensino adotado pelo docente. Este, como já disposto anteriormente, precisa estar em sintonia com o que oferecem os estudantes, com ou sem deficiência visual, pois um mesmo conteúdo é assimilado de modos diversos, tendo em vista que "diferenciação nas práticas de sala de aula são justificadas pelas diferentes inteligências dos alunos" (TOKUHAMA-ESPINOSA, 2008, p.78).

A tabela a seguir traz uma representação dos processos de proposição, aplicação e resultados, conferidos a partir do método SEE BEYOND, considerados os grupos de análise UAM e PcDV. Nela, contemplam--se os procedimentos adotados na aplicação do método. Assim, ao trazer a Metodologia como proposição no processo de ensino aprendizagem, esta é direcionada para aspectos distintos na sua aplicação. Em decorrência dessa relação são obtidos resultados diferentes. Como é apontado na linha [a], a proposição do método, nesse momento, traz a metodologia sincronizada com a relação [Conteúdo + Estímulos], e tem como 


\section{RE ARTE \\ MODA \\ DESIGN}

objetivo gerar interesse pelo conteúdo relativo à Metodologia de Desenvolvimento Projetual (MDP) por parte do estudante.

Tabela 7: Método SEE BEYOND.

\begin{tabular}{|c|c|c|c|}
\hline & RESULTA & $\begin{array}{l}\text { SRUPO ANÁLISE PDV X GRUPO ANÁL } \\
\text { SENVOLVIMENTO PROJETUAL (MDP) }\end{array}$ & UAM \\
\hline CONCEITOS & PROPOSIÇÃo & APLICAÇÃO & RESULTADOS \\
\hline \multirow{7}{*}{ 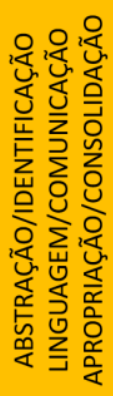 } & a) Metodologia > [Interação] & Conteúdo + Estímulos & Interesse em MDP \\
\hline & b) Metodologia> [Aproximação] & Apropriação & Motivação para MDP \\
\hline & c) Metodologia > [Estimulação sensorial] & $\begin{array}{l}\text { [Visão + Audição] + [Tato + Sistema } \\
\text { Motor }]\end{array}$ & Percepção de corpo e espaço \\
\hline & d) Metodologia > [Composição] & Método + Experiência do grupo & $\begin{array}{l}\text { Estudantes propositivos, } \\
\text { participativos, valorização de } \\
\text { habilidades }\end{array}$ \\
\hline & e) Metodologia > [Coparticipação] & Ampliação de estímulos & $\begin{array}{l}\text { Aproveitamento do processo de } \\
\text { ensino-aprendizagem de MDP }\end{array}$ \\
\hline & f) Metodologia > [Simultaneidade] & Teoria + Prática & Apropriação da MDP \\
\hline & g) Metodologia > [Pesquisa] & Mais informação & Maior qualidade em MDP \\
\hline
\end{tabular}

Fonte: Acervo do autor.

De igual modo, o incentivo à pesquisa, presente na linha [g] visa a propor ao estudante, com ou sem deficiência visual, a apreensão de novos conhecimentos que, em consequência, trazem qualidade quando se desenvolve um projeto.

O que apresenta essa tabela é o resultado da análise comparativa de resultados obtidos pelos três grupos de estudantes, com ou sem deficiência visual, submetidos ao método SEE BEYOND.

\section{CONSIDERAÇÕES}

O Método SEE BEYOND estruturou-se a partir do cruzamento e da interseção entre distintas áreas do conhecimento, dentre elas: revisão bibliográfica acerca dos processos de ensino de $\operatorname{PcD}$ e, especificamente, a PcDV, que enfatizam a relação entre esse grupo e o Ensino Superior; as pesquisas voltadas para o ensino de Design de Moda nas instituições brasileiras, em paralelo à análise de matrizes curriculares de algumas dessas instituições; a relação entre a Neurociência e a Educação, que fundamentou a elaboração de material didático e recursos pedagógicos que possibilitaram o aprendizado a respeito de Design de Moda por estudantes com deficiência visual, e potencializaram o processo projetual de estudantes videntes. 


\section{RE ARTE \\ MODA \\ DESIGN}

| http://www.revistas.udesc.br/index.php/Ensinarmode

O presente texto foi conduzido no âmbito da relação entre a pessoa com deficiência e, em especial, a PcDV e o Ensino Superior. Observou-se que ainda são muitas as barreiras no processo de ensino-aprendizagem, em especial a ausência de material didático e recursos pedagógicos adequados, assim como a carência aos docentes de métodos de ensino voltados para essa parcela de estudantes. A escolha por essa abordagem justifica-se na medida em que proporcionou apresentar o método SEE BEYOND do ponto de vista da Inclusão Social.

Assim, identificou-se que, apesar de ações governamentais como o Projeto INCLUIR, o Decreto Legislativo № 186/2008 que registra a Convenção sobre os Direitos das Pessoas com Deficiência e, a Lei 13.146 - Lei Brasileira de Inclusão da Pessoa com Deficiência (Estatuto da Pessoa com Deficiência), ainda há barreiras que dificultam o ingresso da pessoa com deficiência visual aos bacharelados em Design de Moda.

Verificou-se a lacuna existente, no que diz respeito ao material didático pedagógico inclusivo, relativo a conteúdos necessários aos processos de ensino aprendizagem em Design de Moda. Nesse sentido, na elaboração e no desenvolvimento do Método SEE BEYOND, foram criados e aplicados recursos acessíveis que permitiram a interação entre conteúdos por parte de pessoas com deficiência visual e a ampliação da aprendizagem por estudantes videntes. Tais recursos aliam-se aos conhecimentos prévios dos estudantes para promover interesse e ampliar as capacidades para o desenvolvimento de projetos em Design de Moda.

Os resultados obtidos pelo método não se restringem ao ensino de Metodologia Projetual na área de Design de Moda. Outras experiências em curso permitem dizer que sua aplicação pode ser estendida a outros campos do conhecimento e, não necessariamente, ligadas às artes e ao design.

Considera-se que os estudos que envolvam a inclusão de pessoas com deficiência visual na sociedade e, mais especificamente no Ensino Superior, encontram-se ainda em fase inicial. Tal fato pode ser na verdade um estímulo, pois se vislumbra a possibilidade de surgimento de outras pesquisas que facilitem o acesso e o ingresso de estudantes nos bacharelados em Design de Moda e em outras áreas. 


\section{RE ARTE \\ MODA \\ DESIGN}

\section{REFERÊNCIAS}

AVELAR, S. Moda: globalização e novas tecnologias. São Paulo: Estação das Letras e Cores Editora, 2009.

BARROS, A.B. Processo de inclusão no contexto da deficiência visual: dificuldades, desafios e perspectivas. Dissertação de Mestrado. São Luís, 2013.

BERLIM, L. Moda e sustentabilidade: uma reflexão necessária. São Paulo: Estação das Letras e Cores, 2011.

BRASIL, 2005. Programa de Acessibilidade na Educação Superior (Incluir). Disponível em: $<$ http://portal.mec.gov.br/index.php?option=com_content\&id=17433\&ltemid=817>. Acesso em dez.2014.

BRASIL, 2015. Lei Brasileira de Inclusão da Pessoa com Deficiência (Estatuto da Pessoa com Deficiência) - Lei 13.146. Disponível em: https://goo.gl/YNFeXj, Acesso em jul.2015.

CASTILHO, K. Moda e linguagem. São Paulo: Editora Anhembi Morumbi, 2009.

CASTRO, S.F.; ALMEIDA, M.A. Ingresso e permanência de alunos com deficiência em universidades públicas brasileiras. Rev. Bras. Ed. Esp., Marília, v. 20, n. 2, p. 179-194, abr.-jun., 2014.

CENSO DEMOGRÁFICO 2010.2 Disponível em: <ttp://ftp.ibge.gov.br/Censos/Censo_Demografico_2010/Caracteristicas_Gerais_Reli giao_Deficiencia/tab1_3.pdf>. Acesso em nov.2014.

CHATAIGNIER, G. Fio a fio: tecidos, moda e linguagem. São Paulo: Estação das Letras e Cores Editora, 2006.

CIPINIUK, A.; PORTINARI, D. Sobre métodos de Design. In Design método. COELHO, L. A. L. Rio de Janeiro: Ed. PUC-Rio, 2006.

CLARKE, S.E. Braddock; M., Marie O'. Techno textiles. London: Thames \& Hudson, 2007.

COSENZA, R.M.; GUERRA, L.B. Neurociência e educação: como o cérebro aprende. Porto Alegre: Artmed, 2011.

CRANE, D. Ensaios sobre moda, arte e globalização cultural. São Paulo: Editora Senac São Paulo, 2011.

DAMÁSIO, António R. E o cérebro criou o homem. São Paulo, Companhia das Letras, 2011. 


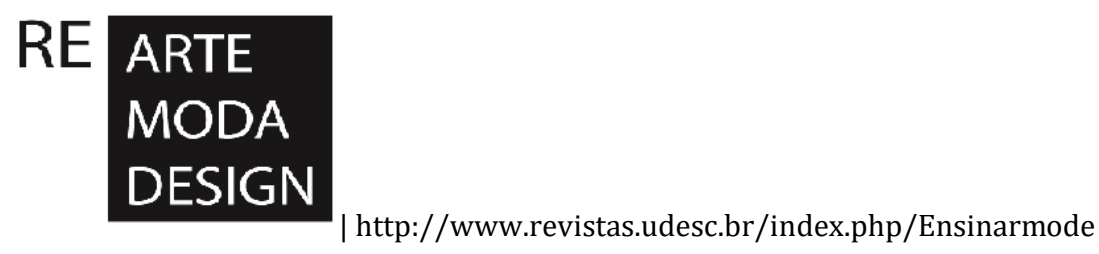

FERRARI, A. L.; CAMPOS, E. De que cor é o vento?: subsídios para ações educativo-culturais com deficientes visuais em museus. Belo Horizonte, MG: Prefeitura, 2001. Disponível em <https://goo.gl/Ld7F1z>. Acesso em ago, 2013.

FIORINI, V. Design de Moda: abordagens conceituais e metodológicas. In: PIRES, D. B. (org.). Design de Moda: olhares diversos. Barueri, SP: Estação das Letras e Cores Editora, 2008.

FLETCHER, K. Moda \& sustentabilidade: design para mudança. São Paulo: Editora Senac São Paulo, 2011.

FORNASIER, C.B.R.; MARTINS, R.F.F.; DEMARCHI, A.P.P. O ensino da disciplina de desenvolvimento de projetos como sistema de gestão de conhecimento. In: PIRES, D.B. (org.). Design de Moda: olhares diversos. Barueri, SP: Estação das Letras e Cores Editora, 2008.

GUIMARÃES, L. A cor como informação: a construção biofísica, linguística e cultural da simbologia das cores. São Paulo: Annablume, 2000.

IZQUIERDO, I. Memória. Porto Alegre: Artmed, 2011.

LIMA, P.A. Educação inclusiva e igualdade social. São Paulo: Avercamp, 2006.

LIMA JÚNIOR, G.C. Conexões táteis: sensorialidade no design de moda no segmento do vestuário masculino. Disponível em <https://goo.gl/zZTD5f>. Dissertação de Mestrado em Design, 2008.

LIMA JÚNIOR, G.C. Design de Moda e Neuroeducação: o desenvolvimento de uma metodologia de desenvolvimento projetual aplicado a pessoas com deficiência visual. Tese de Doutorado em Design, 2016. Disponível em <https://goo.gl/iiysmQ>.

LÖBACH, B. Design industrial: bases para a configuração de produtos industriais. São Paulo: Editora Edgard Blücher, 2001.

MARTINS, S.B. Ergonomia e moda: repensando a segunda pele. In PIRES, D. B. (org.). Design de Moda: olhares diversos. Barueri, SP: Estação das Letras e Cores Editora, 2008.

MATTÉ, V. Educação superior em design: aspectos relevantes na formação profissional. In: BOZZETTI, N.; BASTOS, R. Pensando design 2. (Orgs.). Porto Alegre: Ed. UniRitter, 2008.

NASCIMENTO, V. A modelagem e o projeto em moda. In: RONCOLETTA, M.; FARIA, J. N.; NAVALON, E.; GUILLEN, P.; MARTUCHELLI, A.; CURCE, P. (Org.) Interagindo: design de moda. São Paulo: Editora Esfera, 2012. 


\section{RE ARTE \\ MODA \\ DESIGN}

NUNES, S.; LOMÔNACO, J.F.B. O aluno cego: preconceitos e potencialidades. Revista Semestral da Associação Brasileira de Psicologia Escolar e Educacional, SP. Volume 14, Número 1, jan/jun de 2010.

OLIVEIRA, L.C.P. 2007. Trajetórias escolares de pessoas com deficiência visual: da educação básica ao ensino superior. [Dissertação de Mestrado] Apresentada ao Curso de Pós-Graduação da PUC-Campinas/SP: 2007.

RECH, S. Estrutura da Cadeia Produtiva da Moda. Disponível em: <https://goo.gl//x4Krkk>. Acesso em: mar.2015.

ROSSETTO, E. Sujeitos com deficiência no ensino superior: vozes e significados. 2009. [Tese de Doutorado]. Apresentada ao Programa de PósGraduação em Educação da Universidade Federal do Rio Grande do Sul: Porto Alegre, 2009.

SALTZMAN, A. O design vivo. In: PIRES, Dorotéia B.P. (org.). Design de Moda: olhares diversos. Barueri, SP: Estação das Letras e Cores Editora, 2008.

SACKS, O. Vendo Vozes. São Paulo: Companhia das Letras, 2010.

SORGER, R.; UDALE, J. Fundamentos do design de moda. Porto Alegre: Bookman, 2009.

TOKUHAMA-ESPINOSA, T. N. The scientifically substantiated art of teaching: a study in the development of standards in the new academic field of neuroeducation (mind, brain and education science). Pesquisa de Doutorado. Capella University, 2008. Disponível em: <http://pqdtopen.proquest.com/doc/250881375.html?FMT=ABS>. Acesso em: 30.jan.2015.

Recebido em: 16/02/2018 Aceito em: 17/02/2018 